\title{
Tendências atuais da pesquisa brasileira em Educação Física Parte 1: uma análise a partir de periódicos nacionais
}

CDD. 20.ed. 025.3

796

\author{
Suely ROSA* \\ Jacqueline LETA* \\ *Centro de Ciências \\ da Saúde, Universida- \\ de Federal do Rio de \\ Janeiro.
}

\section{Resumo}

Após poucos séculos de existência, a disciplina de Educação Física (EF) convive, de um lado, com a tradicional valorização de aspectos biológicos e médicos e, de outro, com a recente valorização de aspectos sócio-culturais, políticos e filosóficos. Estes parecem promover uma ruptura com a concepção tradicional de corpo, concepção "biologizada", da EF. Neste contexto, iniciamos um amplo estudo sobre as tendências atuais da pesquisa brasileira em EF. Por meio de uma abordagem bibliométrica, neste trabalho apresentamos uma análise das comunicações científicas em EF, veiculadas em quatro periódicos nacionais, no período de 2000 a 2005.0 objetivo central foi caracterizar um recorte da pesquisa contemporânea brasileira em EF, publicada nestes periódicos, incluindo-se na análise as questões acerca das temáticas de maior interesse dos pesquisadores. 0 estudo seguiu duas etapas principais: a) coleta e organização dos dados e b) categorização e análises quantitativa e qualitativa. As 595 publicações analisadas classificaram-se em 20 áreas do conhecimento sendo fisiologia a de maior incidência $(n=376)$. Publicações com enfoque em áreas mais humanisticas e/ou sociais, como a filosofia, a história, a sociologia do esporte, a psicologia aplicada à educação fisica e ao esporte, a didática, também são encontradas, porém, são ainda minoria. Estes resultados apontam a predominância da concepção biologizada da pesquisa em EF no universo do estudo. As razões podem ser variadas, incluindo o perfil dos periódicos analisados.

Unitermos: Educação Física; Comunicação científica; Periódicos científicos; Bibliometria.

\section{Introdução}

Ao longo da história da humanidade, a prática da atividade física atendeu a diferentes interesses e motivaçoes. O homem primitivo, por exemplo, praticava atividade física seja para sobreviver às condições inóspitas de vida, seja para seus momentos de lazer ou rituais religiosos. Em períodos mais recentes, a prática da atividade física também se associou a outros propósitos, tais como: o militar, o higiênico, o eugênico, o terapêutico, o pedagógico, o rendimento esportivo, o de "fitness" e o da estética corporal (BETTI, 2004; BRACHT, 2007; GHIRALDELLI JÚNIOR, 1991; Marinho, 1980; Soares, Taffarel, Varjal, Castellani Filho, Escobar \& Bracht, 1992) ${ }^{1}$.

Sob a influência do conhecimento gerado, primeiro pelas crenças, depois pela filosofia e, mais tarde pela ciência, teve início, então, o processo de sistematização das atividades físicas. O marco deste processo foi o desenvolvimento de diferentes métodos ginásticos que rapidamente se espalharam pelo mundo, sendo incorporados também pelas instituiçōes de ensino formal. Surge, assim, uma nova disciplina acadêmica, a Educação Física (EF).

A história e a evolução da EF apontam para uma disciplina que busca a valorização e o entendimento do corpo a partir de aspectos biológicos e tecnicistas. Isso se deve, principalmente, à forte influência de médicos e militares, considerados os mentores intelectuais da construção desta área. Segundo BRACHT (1999), os exercícios repetitivos e sistematizados aos quais os militares eram submetidos colocavam em prática o conhecimento médico em torno do corpo, numa perspectiva não apenas terapêutica e educacional, mas também de virilidade. Já MARINHO (1980) argumenta que os militares dominavam a técnica dos exercícios, mas foram os médicos e cientistas que contribuíram para formar o corpo de conhecimento em torno da prática das atividades físicas, com base na fisiologia do exercício. 
Por meio da produção bibliográfica das primeiras revistas da área de EF, também, é possível identificar as concepçôes militaristas e ideologias políticas que permeavam a construção dessa disciplina em diferentes momentos. Assim, o QUADRO 1 apresenta uma relação das primeiras revistas brasileiras de EF, acompanhada de uma descrição de perfil.

QUADRO 1-Visão evolutiva e o perfil dos primeiros periódicos da área de EF.

Fonte: Adaptada de DACOSTA (2005) citado por Ferreira Neto (2005, p.776) e Melo (2005).

\begin{tabular}{|c|c|c|c|}
\hline Período & Revista & Chancela & Perfil \\
\hline $1932-1960$ & Revista EF & Escola de EF do Exército. & $\begin{array}{l}\text { Produzia e veiculava doutrina sobre EF aplicada ao } \\
\text { Exército, co-produzia e veiculava um projeto na- } \\
\text { cional para a área. A partir da década de } 60 \text {, volta- } \\
\text { se, exclusivamente, para as pesquisas com enfâse na } \\
\text { preparação física da tropa e de atletas de alto nível. }\end{array}$ \\
\hline $1932-1945$ & $\begin{array}{l}\text { Revista Educação } \\
\text { Physica }\end{array}$ & $\begin{array}{l}\text { Revista técnica de ensino } \\
\text { de caráter privado e co- } \\
\text { mercial editada pela Com- } \\
\text { panhia Brasil Editora. }\end{array}$ & $\begin{array}{l}\text { Buscava divulgar os princípios científicos, } \\
\text { a formação profissional, os esportes, os fins } \\
\text { morais e sociais, colaborando com os gover- } \\
\text { nos e instituições particulares na implanta- } \\
\text { ção e consolidação da Educação Física no País. }\end{array}$ \\
\hline $1941-1958$ & $\begin{array}{l}\text { Boletim de } \\
\text { Educação Física }\end{array}$ & 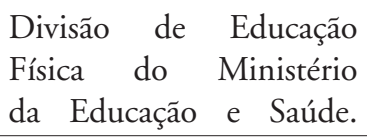 & Veiculava a política e ações governamentais na área. \\
\hline $1944-1952$ & $\begin{array}{l}\text { Revista } \\
\text { Brasileira de } \\
\text { Educação Física }\end{array}$ & $\begin{array}{l}\text { Revista de ensino de ca- } \\
\text { ráter privado e comercial } \\
\text { feita pela Editora A Noite. } \\
\text { A coordenação editorial é } \\
\text { de Inezil Penna Marinho. }\end{array}$ & $\begin{array}{l}\text { Há evidências de que esta é uma revista de } \\
\text { síntese do pensamento brasileiro para a área. }\end{array}$ \\
\hline $1945-1966$ & $\begin{array}{l}\text { Arquivos da } \\
\text { ENEFD }\end{array}$ & $\begin{array}{l}\text { Criada e vinculada à Uni- } \\
\text { versidade do Brasil (UB). }\end{array}$ & $\begin{array}{l}\text { Difusão de conhecimentos por meio da divulga- } \\
\text { ção de informações obtidas a partir de pesquisas. }\end{array}$ \\
\hline
\end{tabular}

Não obstante a forte influência médico-militar, a disciplina de EF buscou, mais recentemente, valores e referenciais em outras disciplinas, especialmente naquelas das ciências humanas e sociais. Esse processo parece ter se iniciado nos movimentos estudantis, políticos e culturais que ocorreram em várias partes do mundo no final dos anos de 1960 e incidiram profundamente sobre a pedagogia (CAMBI, 1999). Elementos dessa nova pedagogia foram incorporados no "corpus" teórico da EF nos anos 70, ainda que na sua versão tecnicista, via didática. Porém, a perspectiva da EF como prática social surge mais fortemente nos anos de 1980 (OliveIRA, 1994).

Assim, após poucos séculos de existência, a disciplina de Educação Física convive com a tradicional valorização de aspectos biológicos e médicos e com a recente valorização de aspectos sócio-culturais, políticos e filosóficos, os quais parecem promover uma ruptura com a concepção tradicional, "biologizada" da EF. Transitando entre uma "Educação do físico" e uma "Educação pelo físico", os profissionais e, em especial, os pesquisadores em Educação Física se deparam com as dualidades da área, que podem ser motivo de disputas internas para a área como um todo. Isso fica claro na discussão encaminhada por Betti, Carvalho, Daolio e Pires (2004), os quais também apontam outras dicotomias na área de EF: a pesquisa em EF deve se voltar mais para uma pesquisa básica ou para uma pesquisa aplicada? A área e a formação do profissional em EF devem ter enfoques mais acadêmico ou somente profissional?

No presente trabalho, um recorte da publicação científica brasileira em EF foi adotado para caracterizar a pesquisa contemporânea nacional em EF. Para esta abordagem foram utilizados quatro periódicos nacionais da área, sobre os quais realizamos análises acerca das temáticas de maior frequência nestes veículos. Assim, empregando-se uma abordagem bibliométrica foi possível estabelecer variáveis de desempenho, que retratam uma parte do cenário da pesquisa em EF no Brasil. 


\section{Procedimentos metodológicos}

Segundo Ferreira Neto e Nascimento (2002), os principais periódicos em EF no Brasil são: Revista Brasileira de Ciências do Esporte, Revista Motus Corporis, Revista Paulista de Educação Física (atual Revista Brasileira de Educação Física e Esporte), Revista Brasileira de Ciência e Movimento, Revista Movimento, Revista Motrivivência, Revista Mineira de Educação Física, Revista de Educação Física/UEM, Revista Motriz, Revista Licere, Revista Kinesis. Apesar de reconhecermos a importância destes periódicos para a difusão do conhecimento na área, optamos por um recorte a partir dos 59 periódicos disponíveis on-line no Portal dos Periódicos Capes em 2006. Deste total, somente quatro eram brasileiros. Como o nosso interesse estava centrado na produção científica da EF nacional, optamos por periódicos deste último grupo. Importante destacar que, muito embora o recorte deste trabalho exclua uma parte das revistas de EF no país (especialmente, aquelas indicadas por FerReira NeTO e NASCIMENTO que à época não se encontravam disponíveis no Portal), entendemos que a análise dos dados coletados nesta amostra cobre não apenas o conhecimento científico em EF validado e referendado pela CAPES, mas também aquele de maior visibilidade no país.

Uma breve análise dos periódicos selecionados revela alguns detalhes e diferenças importantes entre eles, que podem explicar alguns dos resultados que apresentaremos. A Revista Brasileira de Ciência do Movimento (RBCM), lançada em 1987 pela a Universidade Católica de Brasília, teve parceria firmada com o Centro de Estudos do Laboratório de Aptidão Física de São Caetano do Sul (CELAFISCS) a partir de 1999. Tem por missão publicar resultados de pesquisas originais, revisōes, comentários e notas científicas em Ciências do Esporte, com ênfase no movimento humano.

Já a Revista Brasileira de Medicina do Esporte (RBME) é a revista oficial da Sociedade Brasileira de Medicina do Esporte. Desde 1999, passou a ser publicada com periodicidade bimensal e tem por "missão disseminar a produção científica nas áreas de ciências do exercício e do esporte”. A terceira revista, a Revista Brasileira de Educação Física e Esporte (RBEFE), é uma publicação trimestral da Escola de Educação Física e Esporte da Universidade de São Paulo e tem por objetivo publicar estudos acerca do movimento humano relacionados à EF, Esportes e áreas afins. Até 2004, o periódico intitulava-se Revista Paulista de Educação Física. Finalmente, a Revista Mackenzie de Educação Física e Esporte (REMEFE) está vinculada à Faculdade de Educação Física da Universidade Presbiteriana Mackenzie e seus principais temas de interesse são: 1) Dimensões Pedagógicas e Sociais da Educação Física e Esporte e 2) Dimensões Biodinâmicas da Educação Física e Esporte.

A coleta dos dados das publicações destes periódicos estendeu-se por cerca de seis meses, sendo finalizada em janeiro de 2007. No total, foram coletadas 595 publicações. A análise das publicações varreu o período de 2000 a 2005 , que variou de acordo com a história e a data em que cada revista se tornou disponível on-line (QUADRO 2).

A análise das 595 publicaçôes contou com duas etapas principais: a) coleta e organização dos dados; b) categorização e análises quantitativa e qualitativa dos mesmos. Para a coleta, a página de cada periódico foi acessada individualmente e suas respectivas publicaçôes foram salvas em formato pdf. Uma a uma estas publicaçōes foram analisadas e, a partir delas, diversas informações foram, manualmente, coletadas e organizadas em uma planilha, constituindo, assim, um banco de dados da Produção Científica Brasileira em $\mathrm{EF}$ (PCBEF). As informações contidas neste banco de dados incluem: 1) Autoria dos trabalhos - Autoria pessoal, autoria múltipla, gênero dos autores; 2) Tipologia dos artigos - Artigo Original, Revisão, Seção Especial e Outros (neste último, incluem-se publicaçóes como Ponto de Vista, Opiniāo, Relato de Caso e Diretriz); 3) Instituições de Origem dos Primeiros Autores, e 4) Publicações internacionais e co-publicações.

QUADRO 2 - Periódicos analisados: período e total de artigos.

\begin{tabular}{|l|c|c|}
\hline \multicolumn{1}{|c|}{ Títulos } & Período & Artigos \\
\hline A Revista Brasileira de Ciência do Movimento - RBCM & $2000 / 2005$ & 246 \\
\hline Revista Brasileira de Medicina do Esporte - RBME & $2001 / 2005$ & 172 \\
\hline Revista Brasileira de Educação Física e Esporte - RBEFE & $2000 / 2005$ & 135 \\
\hline Revista Mackenzie de Educação Física e Esporte - REMEFE & $2002 / 2005$ & 42 \\
\hline Total & & $\mathbf{5 9 5}$ \\
\hline
\end{tabular}


Em um segundo momento, buscou-se a categorização da grande área, da área e da temática principal de cada uma das 595 publicaçôes. Para definir áreas de conhecimento nos artigos foi realizada, inicialmente, a análise das palavras-chave, dos resumos e, quando necessário, a leitura completa do artigo. Isso possibilitou um melhor entendimento das motivaçôes, do objeto de estudo e do objetivo de cada publicação pela especialista da área (Suely Rosa). Uma vez conhecido o escopo de uma publicação, esta foi classificada em uma das nove grandes áreas de conhecimento que constam da lista elaborada pela Coordenadoria de Aperfeiçoamento de Pessoal de Ensino Superior (CAPES). Em nossa análise, no entanto, foram identificados artigos que transitavam com temáticas em sete dessas grandes áreas: Ciências Biológicas, Ciências da Saúde, Medicina, Ciências Exatas e da Terra, Ciências Sociais Aplicadas, Ciências Humanas e Linguística, Letras e Artes. Portanto, no pool de artigos analisados não encontramos nenhum nas grandes áreas das Ciências Agrárias e das Engenharias.

Uma vez classificadas em grandes áreas, foi possível identificar a área do conhecimento de cada uma das 595 publicações analisadas. No total, estes trabalhos classificaram-se em 20 disciplinas: nas Ciências Biológicas: Anatomia, Biofísica, Biologia, Bioquímica, Fisiologia, Neurofisiologia; nas Ciências da Saúde: Educação Física e Saúde Coletiva; na Medicina: Medicina e Reabilitação; nas Ciências Exatas e da Terra: Ciências da Computação; nas Ciências Humanas: Antropologia, Educação, Filosofia, História, Psicologia, Sociologia; nas
Ciências Sociais Aplicadas: Administração; e na área de Linguística, Letras e Artes: Linguística e Artes.

Finalmente, adotou-se uma terceira classificação referente ao escopo/abordagem central de trabalho: 1) abordagem biológica e 2) abordagem não biológica (que na maioria tinham o caráter humanístico). O primeiro grupo, abordagem biológica, engloba os trabalhos que foram categorizados nas grandes áreas das Ciências Biológicas, Ciências da Saúde, Medicina e apresentaram um conteúdo no qual o uso da atividade física atendeu às questôes ligadas aos aspectos anatômicos, bioquímicos, biofísicos, biológicos, fisiológicos, médicos, de reabilitação e da saúde do ser humano. Já o segundo grupo, abordagem não biológica engloba os trabalhos que foram classificados nas grandes áreas das Ciências Exatas e da Terra, Ciências Sociais Aplicadas, Lingüística, Letras e Artes, Ciências Humanas, ou seja, aqueles que apresentam questóes ligadas a aspectos como sociológicos, antropológicos, artísticos, educacionais, filosóficos, entre outros.

Todas as 23 publicações classificadas na disciplina "Educação Física e Esportes", que compõe a grande área das Ciências da Saúde, foram classificadas como tendo abordagem não biológica. Nestes casos, as temáticas eram relacionadas às técnicas, táticas esportivas e estudos olímpicos, não fazendo, portanto, nenhuma referência nem à bioquímica, anatomia, fisiologia, ou outro aspecto relacionado à abordagem biológica.

Para melhor visualizar este processo de categorização são apresentados dois exemplos de publicaçóes (QUADRO 3).

QUADRO 3 - Exemplo da categorização dos artigos.

\begin{tabular}{|l|c|c|c|c|}
\hline \multicolumn{1}{|c|}{ Título } & Temática & Disciplina & Grande área & Abordagem \\
\hline $\begin{array}{l}\text { Efeito do treinamento físico } \\
\text { com natação sobre o sistema } \\
\text { cardiovascular de ratos normo- } \\
\text { tensos. }\end{array}$ & Treinamento & Fisiologia & Ciências Biológicas & Biológica \\
\hline $\begin{array}{l}\text { A estética como um valor na } \\
\text { educação física. }\end{array}$ & Estética & Filosofia & Ciências Humanas & Não biológica \\
\hline
\end{tabular}

Este processo de categorização foi validado por uma análise complementar realizada pela Dra. Verônica Salerno Pinto, professora e pesquisadora da Faculdade de Educação Física e Desportos da Universidade Federal do Rio de Janeiro. 


\section{Resultados}

Os resultados apresentados a seguir estão organizados em dois blocos principais: 1) uma caracterização geral da pesquisa atual em EF e 2) tendências temáticas e de abordagem da pesquisa em EF.

\section{Caracterizando a pesquisa brasileira atual em EF: quantos, quem e onde estão os pesquisadores da área?}

A análise da autoria de publicações pode revelar informaçôes importantes acerca do perfil de uma dada comunidade científica, seja ela de um país, instituição ou área, por exemplo. As análises mais comuns de autoria são: a distribuição de LOTKA (1926) e a contagem de autores por publicação. Essa última análise foi realizada para as 595 publicações em EF de nossa amostra (FIGURA 1). É possível verificar que a maior parte destas publicaçōes tem de um a três autores e somam 390, o que representa $65,5 \%$ do total analisado. O perfil encontrado para as publicações em EF assemelha-se ao das áreas de Ciências Humanas e Sociais. As características intrínsecas destas áreas favorecem o trabalho isolado ou com um número reduzido de colaboradores. Por outro lado, as áreas de ciências ditas "hard sciences", se caracterizam por um alto e crescente grau de colaboração que se reflete no número médio de autores por publicações, o qual, em média, é superior aquele encontrado para as Ciências Humanas e Sociais ${ }^{3}$.

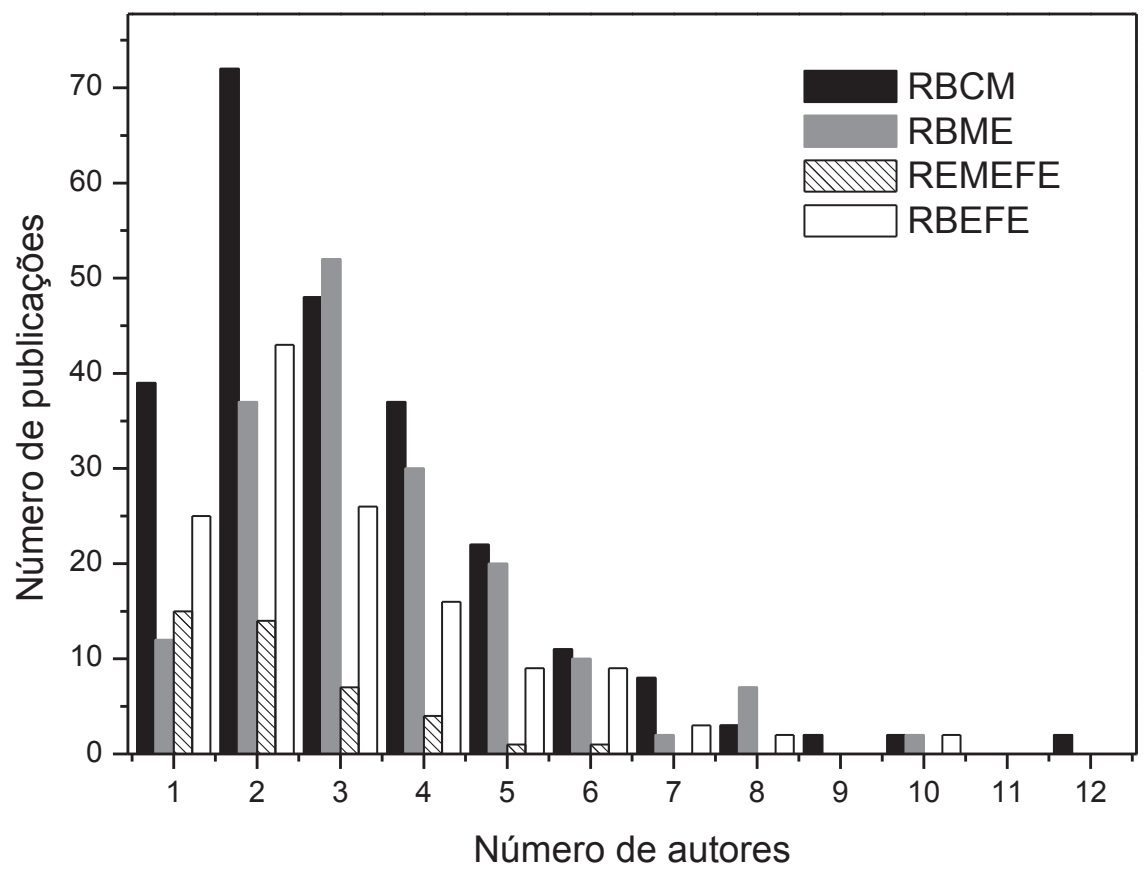

FIGURA 1 - Publicações de EF segundo o número de autores e periódicos.

Outra variável analisada foi o sexo dos autores. Historicamente, a ciência sempre foi tida como uma atividade realizada por homens. No Brasil, a participação cada vez maior de mulheres nessa atividade inicia-se nos anos de 1980, como um reflexo da crescente entrada delas no mercado de trabalho como um todo. Hoje, elas são maioria entre a totalidade dos matriculados e concluintes do ensino superior no país (INEP, 2006). Na atividade científica, dados do Conselho Nacional de Desenvolvimento Científico e Tecnológico (CNPQ, 2004) mostram que o número e a fração de mulheres têm crescido significativamente nos últimos anos. Entre os 5.238 pesquisadores-doutores cadastrados em 2004, 42,5\% eram mulheres; entre aqueles da área de saúde, que inclui os da EF, esta fração é de 53\%. Já para os 479 pesquisadores-doutores cadastrados neste mesmo ano na EF, 199 eram mulheres, o que representa 41,5\% do total, uma fração próxima ao encontrado para o país. Na análise das 595 publicações, considerando apenas o primeiro autor (FIGURA 2), encontramos, na REMEFE, um panorama semelhante aquele encontrado para os pesquisadores da área de EF: as mulheres autoras representam cerca de $45 \%$ do total de autores. Fração menor de mulheres autoras é encontrada na RBEFE, RBME e na RBCM. 


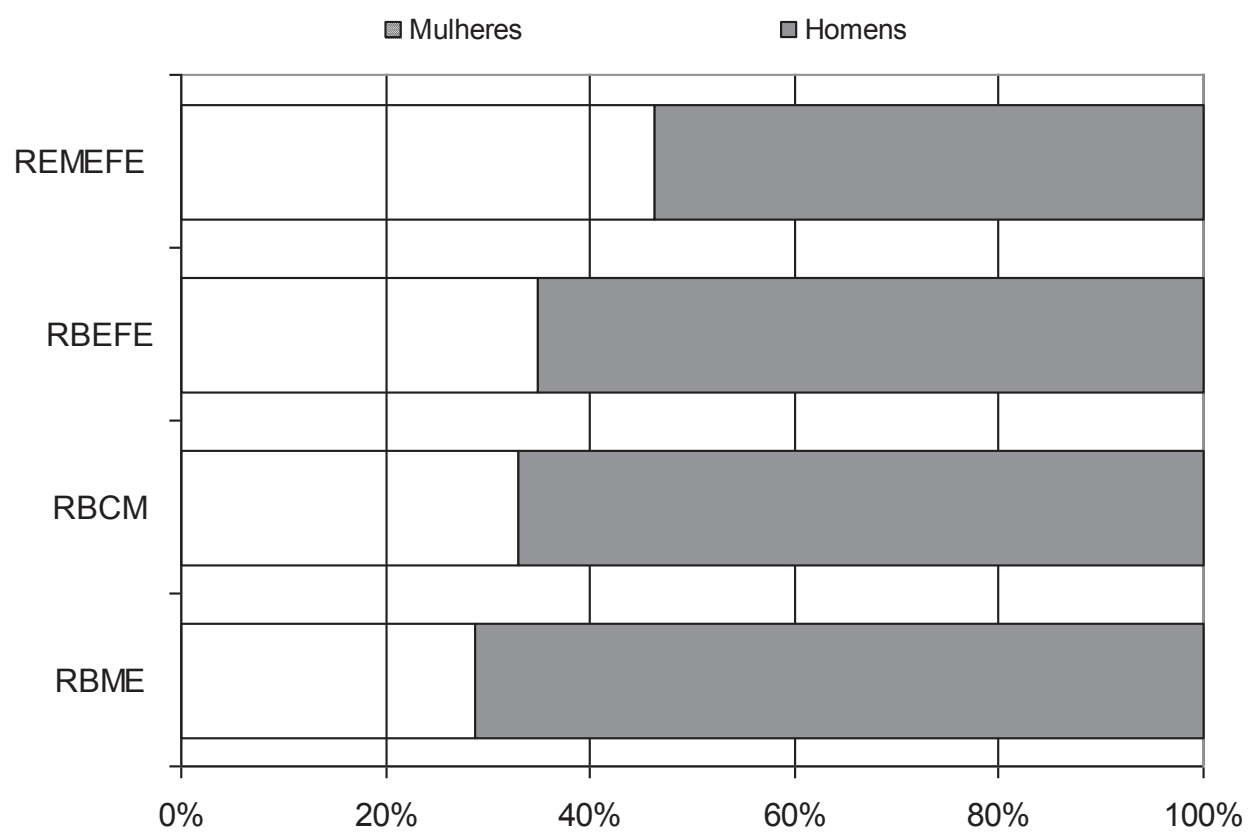

Autores, \%.

FIGURA 2 - Autoria das publicações de EF segundo sexo e periódicos.

Uma última variável que caracteriza o perfil dos autores da EF, majoritariamente homens, éa instituição a qual estão vinculados. A FIGURA 3 mostra as instituições cujos autores são mais frequentes em nossa análise. A soma das publicações destas instituiçôes equivale a 374 (62,85\% da amostragem). Dentre a totalidade de primeiros autores, observamos que a maior parte deles tem vínculo com a USP (Universidade de São Paulo), que são responsáveis por 85 publicações $(14,28 \%$ do total). Em seguida, encontramos 50 publicaçōes $(8,4 \%)$ cujos primeiros autores têm vínculo com UNESP (Universidade Estadual de São Paulo). A grande presença de autores da USP indica uma forte produção dessa instituição na área EF. Entretanto, é importante salientar que a USP é a instituição brasileira com o maior número de publicaçōes científicas do país, na maior parte das áreas (Leta, Glanzel \& Thujs, 2006), e, portanto, a concentração de publicações em EF nesta instituição se configura como algo já esperado.

A análise individual das revistas mostra que as publicaçōes originadas por autores filiados à USP ou são as mais frequentes, tal como na RBCM e RBEFE, ou estão entre as mais frequentes, RBME e RMEFE. No caso da RMEFE, predominam as publicações cujos autores estão filiados à Universidade Presbiteriana Mackenzie (UPM), o que pode ser explicado pelo fato de a revista ser de responsabilidade desta Universidade, o que parece caracterizar um caso de endogenia. Já na RBME, o predomínio é de publicaçôes originadas na Universidade Gama Filho (UGF), seguida de publicações com afiliação na USP e na UNESP (dados não apresentados).

$\mathrm{Na}$ análise por setor, público e privado, verificamos que dos 595 endereços dos primeiros autores, 347 (58,31\%) se originaram em instituições públicas, $208(34,95 \%)$ em instituiçõos privadas enquanto 39 (6,55\%) não apresentavam nenhuma afiliação (dados não apresentados). Esses dados contrastam, no entanto, com os dados sobre a afiliação dos autores das publicações brasileiras em periódicos internacionais, catalogados na base de dados do Institute For SCIENTIFIC InFormation - ISI (2008), em que as universidades públicas brasileiras são responsáveis por 80\% (LETA, GLANZEL $\&$ Thujs, 2006).

A análise individual das revistas mostra que a RBEFE e a RBME apresentam um número maior de publicações com autores de afiliação em instituiçōes públicas, enquanto a REMEFE, vinculada à universidade particular, apresenta um número maior de publicações com afiliação em instituições privadas (dados não apresentados). 


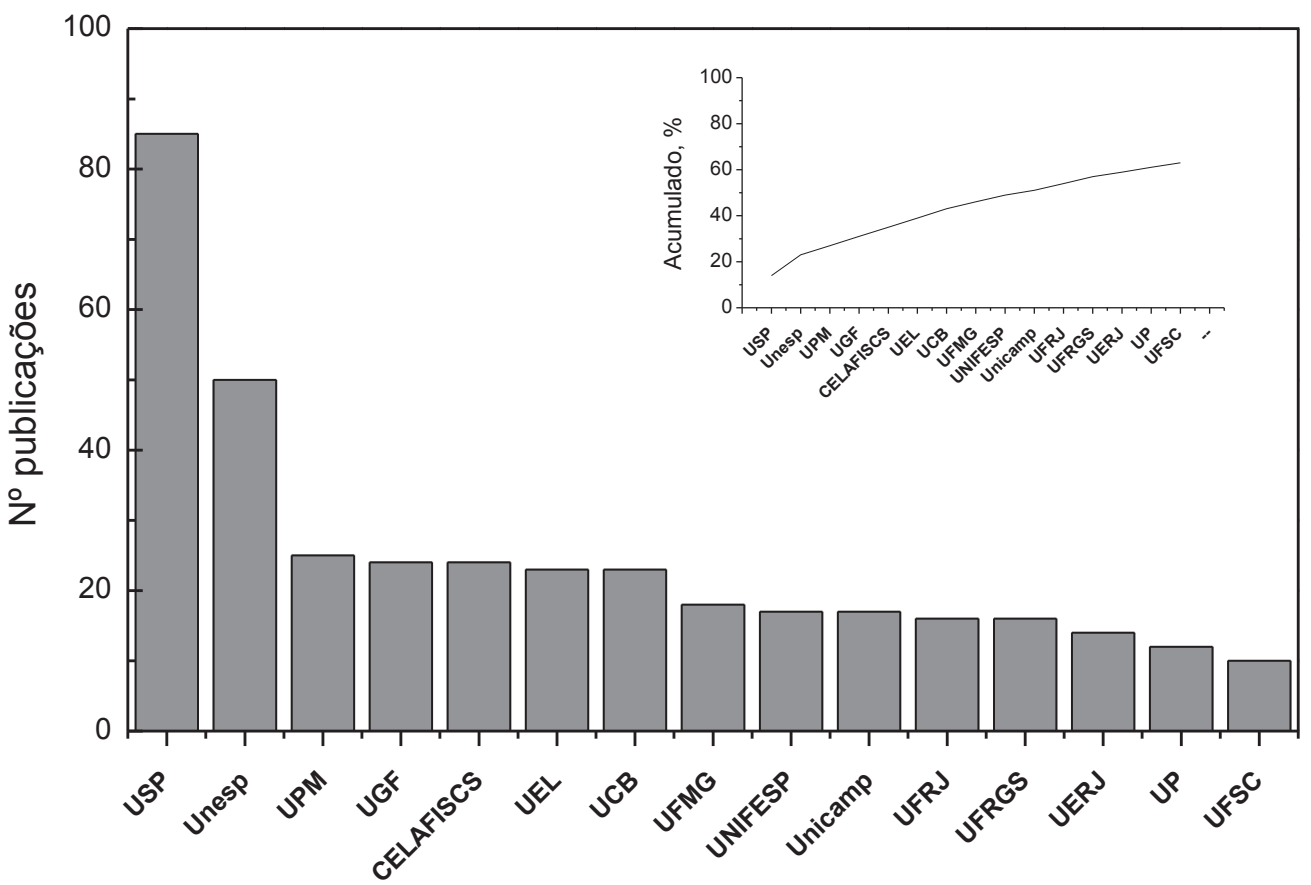

FIGURA 3 - Número e distribuição acumulada (“inset”) das publicações em EF, segundo as principais instituições de afiliação dos autores.

\section{Caracterizando a pesquisa brasileira atual em EF: qual o formato e as parcerias?}

A análise de formato das publicações pode seguir por diversos caminhos, por exemplo, tipologia, desenho experimental, paginação. Em nosso estudo, optamos pela tipologia das publicações para discutir o formato da pesquisa atual em EF em periódicos nacionais. Importante salientar que as quatro revistas analisadas elaboram e apresentam em seus manuais de submissão, as tipologias que interessam para publicação, que inclui artigos originais, de revisão, seção especial, ponto de vista, opinião, relato de caso. Em todos os casos, esta
USP (Universidade de São Paulo); UNESP (Universidade Estadual Paulista); CELAFISCS (Centro de Estudos do Laboratório de Aptidão Física de São Caetano do Sul); UGF (Universidade Gama Filho); UPM (Universidade Presbiteriana Mackenzie); UCB (Universidade Católica de Brasília); UEL (Universidade Estadual de Londrina); UNIFESP (Universidade Federal de São Paulo); UNICAMP (Universidade Estadual de Campinas); UFRJ (Universidade Federal do Rio de Janeiro); UERJ (Universidade do Estado do Rio de Janeiro); UFRGS (Universidade Federal do Rio Grande do Sul); UFMG (Universidade Federal de Minas Gerais); UFSC (Universidade Federal de Santa Catarina); UCB/RJ (Universidade Castelo Branco); UniFMU (Centro Universitário das Faculdades Metropolitanas Unidas); UFPR (Universidade Federal do Paraná); UFU (Universidade Federal de Uberlândia).

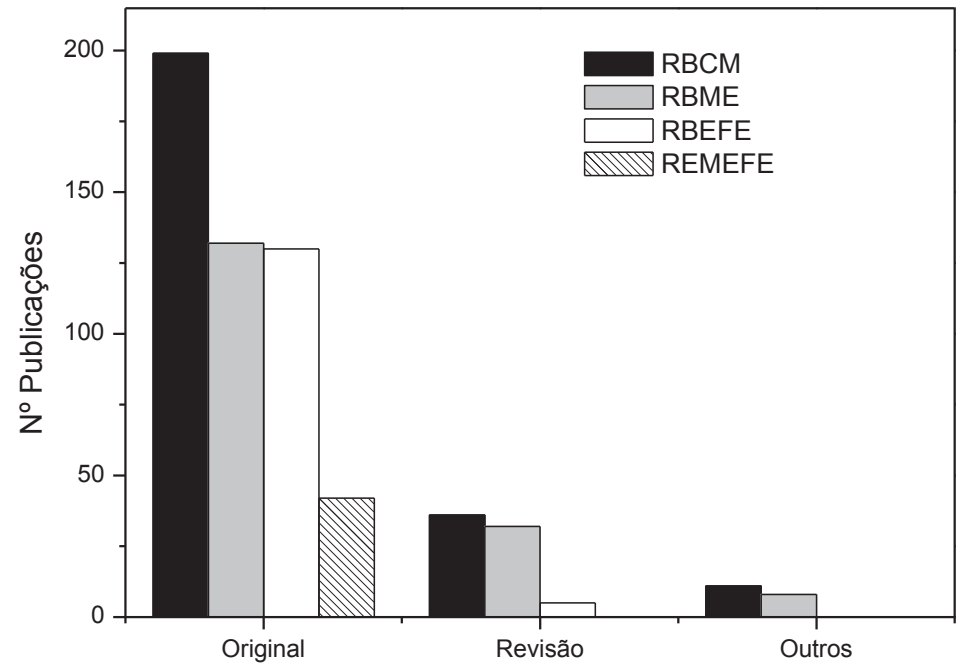

FIGURA 4 - Publicações de EF segundo a tipologia e periódicos. 
Além da tipologia das publicaçôes, analisamos também a questão das parcerias na pesquisa atual em EF. É fato que o número de parceiros na pesquisa tem crescido significativamente nas últimas décadas. Isso se deve ao encarecimento das novas tecnologias e à qualificação cada vez mais especializada dos pesquisadores, em ambos os casos há necessidade de grandes investimentos (KATZ \& MARTIN, 1997). No Brasil, a análise das publicações indexadas na base de dados do ISI (2008) mostra que a fração de publicações brasileiras com parceria internacional representa pouco mais de 30\% do total de publicações (Glanzel, Leta \& Thijs, 2006). Cenário como este, no entanto, não é observado para as publicações nacionais em EF. Das 595 publicações, apenas 26 (4,3\%) são publicaçôes em parceria com outros países (FIGURA 5). A baixa cooperação com pesquisadores de outros países pode ser explicada pelo fato de serem periódicos nacionais sem projeção internacional. Da mesma forma, pode ser um indicativo de uma área onde a cultura do trabalho colaborativo ainda não se consolidou, seja por dificuldades linguísticas que prejudicam o estabelecimento de contatos com parceiros de línguas estrangeiras, seja por conta de ainda seus estudos estarem voltados principalmente a questões de interesse nacional.

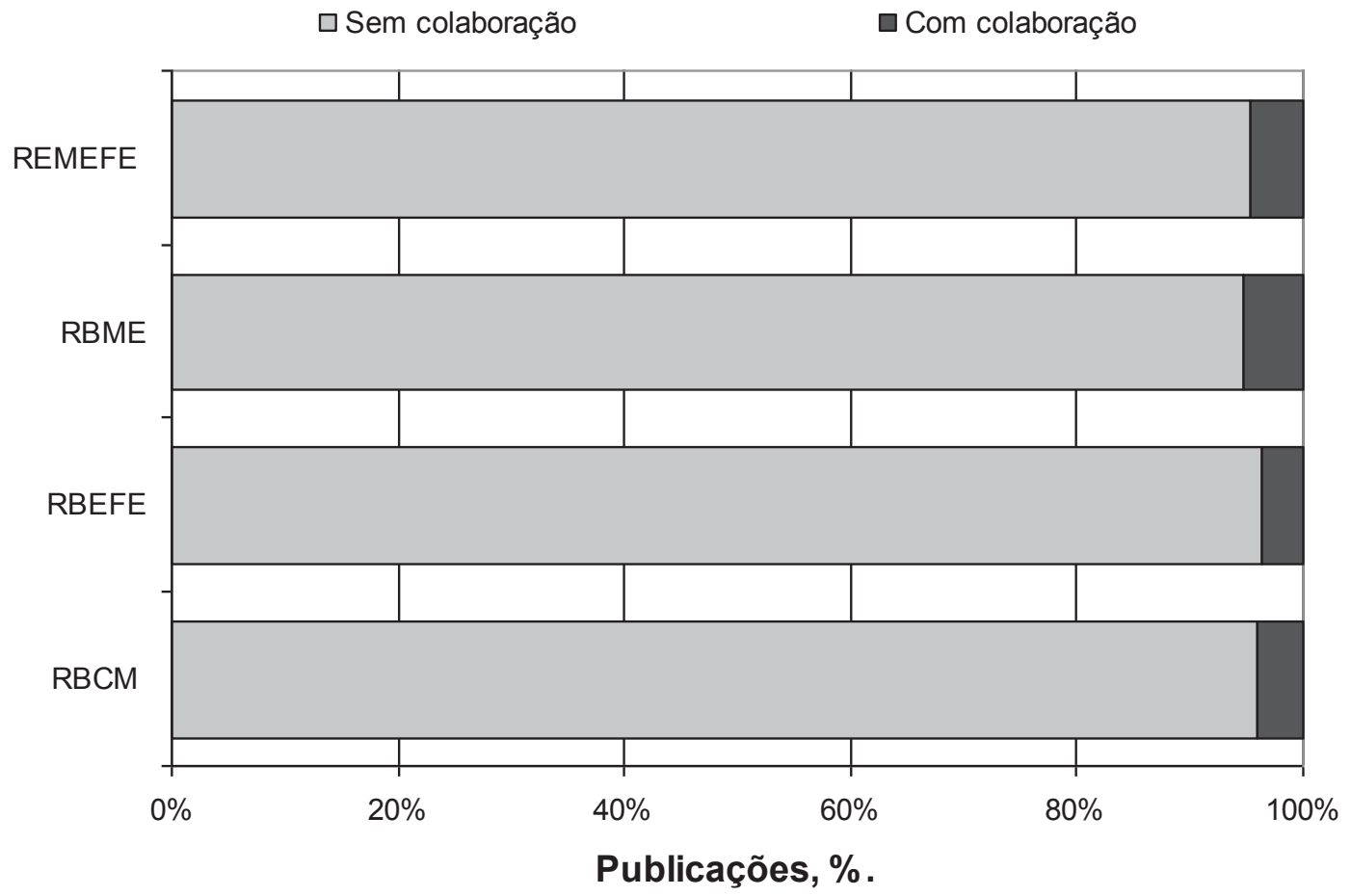

FIGURA 5 - Publicações de EF com e sem colaborações internacionais.

Dentre os poucos parceiros internacionais, predominam aqueles de países da Europa e da América do Norte. Neste caso, repete-se o cenário da pesquisa nacional (Leta \& Meneghini, 2002). Assim, se por um lado os autores brasileiros pouco buscam a colaboração de parceiros internacionais, quando isso acontece, a tendência é buscá-la nos países do hemisfério norte, seja por suas tradições em pesquisa, seja pelas lideranças específicas da área.

\section{Temáticas e abordagens na pesquisa em EF: um campo em consolidação?}

$\mathrm{Na}$ história da construção da área de EF, a forte presença e influência dos conhecimentos biológicos e em saúde são facilmente identificadas. $\mathrm{O}$ quanto a pesquisa brasileira atual nesta área reflete, ainda hoje, a sua construção histórica? Quais as temáticas mais frequentes nestes estudos? Qual importância que a pesquisa em EF dá a outros aspectos que não os biológicos? A fim de responder estas perguntas, o escopo de cada uma das 595 publicações foi analisado, o que permitiu definir uma temática para cada uma delas e uma classificação posterior em disciplina, grande área até chegar à de abordagem.

Partindo da análise de grande área do conhecimento, 431 publicaçôes (72,43\% do total) foram classificadas na grande área de Ciências Biológicas. A soma deste total com as publicações classificadas em Medicina (2) e em Ciências da Saúde (26) corresponde a 459 publicaçôes, ou seja, $77,14 \%$ do total. Em contraste, as publicaçóes 
classificadas nas grandes áreas de Ciências Humanas (127), Ciências Sociais Aplicadas (5), Linguística, Letras e Artes (2) e Ciências Exatas e da Terra (2) somam 136, o que representa $22,85 \%$ do total analisado. Percebe-se, assim, que apenas $1 / 5$ do conhecimento divulgado nestes periódicos se destina às áreas que não são Biologia ou Saúde.

A análise das publicaçóes segundo as disciplinas em que melhor se enquadram seus escopos revelou uma característica importante: a presença expressiva de publicações em Fisiologia $(n=376)$. A forte presença desta disciplina nos trabalhos explica a prevalência de publicaçôes nas Ciências Biológicas. Publicações classificadas em outras disciplinas obviamente também contribuíram para este cenário, e, as principais foram: Bioquímica (18 publicações), Biofísica (14), Anatomia (9), Biologia (8) e Neurofisiologia (4). Já nas publicações classificadas nas áreas do conhecimento que compõem a grande área das Ciências Humanas e afins, verificou-se a prevalência de publicações nas disciplinas: Psicologia (54), Educação (29), Sociologia (28), Filosofia (11) e História (6).
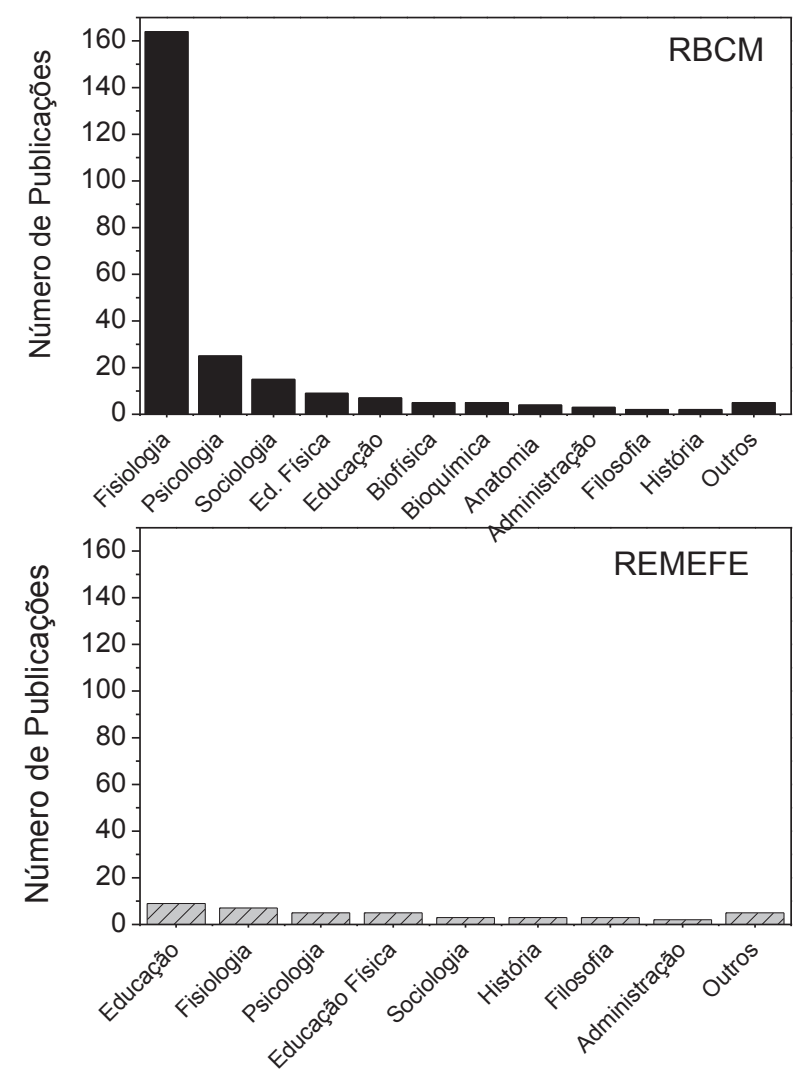

Entre as publicações classificadas como Psicologia, as temáticas mais frequentes tratavam sobre Psicologia do esporte (27), seguidas de Aprendizagem motora (13). Já naquelas da Educação, foram encontradas temáticas ligadas à Formação do profissional em EF e Esporte (6), Currículo e EF (4), EF escolar (4), ensino (4) e Metodologia e estratégias de ensino (3). Para aquelas com escopo em Sociologia, as temáticas que predominavam estavam ligadas à Sociologia aplicada à EF e Esporte (11), Questôes de gênero (5) e Lazer (4) enquanto em Filosofia as temáticas mais frequentes relacionadas tratavam de questôes ligadas à Ética e Estética (valor) na EF (8) e Filosofia aplicada a EF e Esporte (3).

Tendência semelhante é também observada na análise de disciplinas segundo os periódicos (FIGURA 6). Com exceção da RMEFE, é visível também a preponderância de publicações cujo escopo se enquadra em Fisiologia. Na RMEFE, predominam as publicaçóes cujo foco central enquadra-se em Educação (9), as quais representam $21,4 \%$ do total da revista.
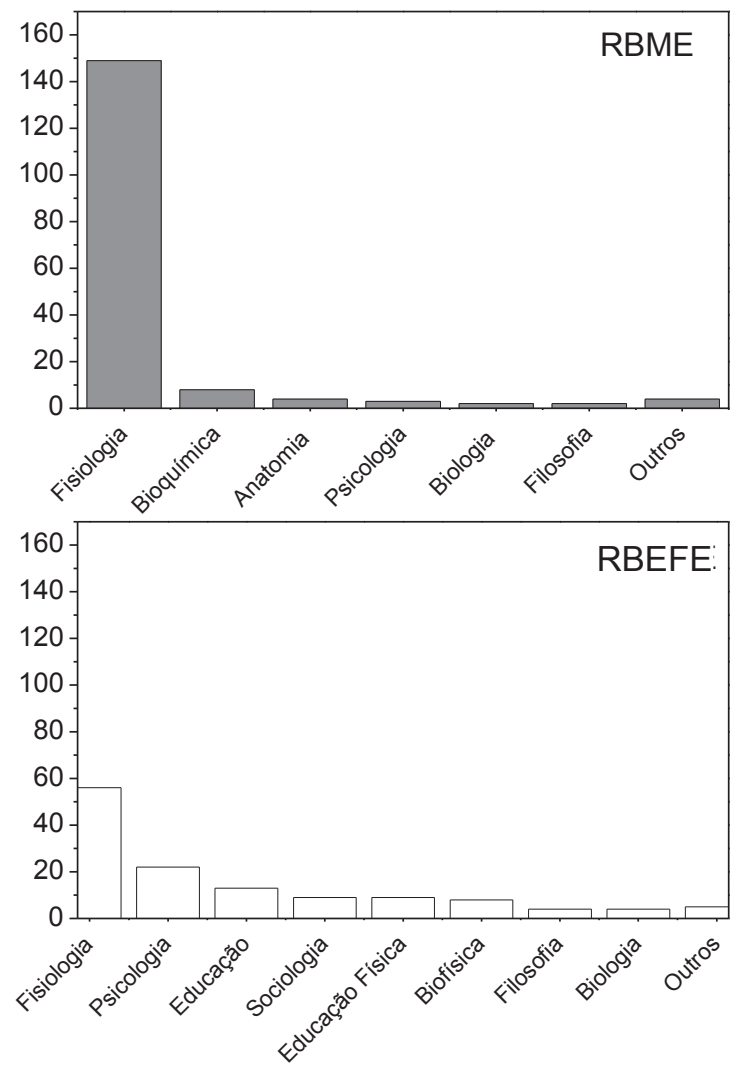

FIGURA 6 - Publicações nacionais em EF segundo a disciplina e periódico.

As publicaçôes classificadas em Fisiologia apresentavam várias temáticas, a mais frequente tratava sobre "Testes e instrumentos de análise” (119). Outra temática bastante encontrada nestas publicações relacionavase à "Fisiologia do exercício" $(\mathrm{n}=52)$. Alimentação/ suplementação e exercício (26), Atividade física (26), Atividade física envolvendo idosos (24), Treinamento (24), Cineantropometria (19), Força muscular (22), Aptidão física (11) e Hidratação no exercício (7) foram também temáticas frequentes nesta área. Importante 
mencionar que para a realização de muitos desses estudos são necessários instrumentos, equipamentos e laboratórios que demandam grandes investimentos, entretanto, apesar dessa condição, as pesquisas em fisiologia foram as que prevaleceram. Isso sugere o forte diálogo da pesquisa em EF com a disciplina da Fisiologia, demonstrando a intensa influência da grande área biológica neste campo de conhecimento.

Os dados de disciplina e grandes áreas foram reunidos em dois únicos grupos: 1) publicaçôes com abordagem biológica e 2) publicações com abordagem não biológica. No total, 435 publicações de nossa análise têm abordagem biológica (73\%) enquanto 160 publicaçōes (27\%) têm abordagem não biológica. A análise por periódicos mostra um cenário semelhante: com exceção da REMEFE e RBEFE, os outros dois periódicos mostram uma tendência absoluta de publicaçóes cuja abordagem é de caráter biológico: a RBCM com 182 publicações deste tipo (74\%), a RBME com 166 (96\%), a RBEFE com 77 (57\%) publicaçôes, apresenta valores mais equilibrados e a REMEFE com 10 (24\%) (FIGURA 7).

Não biológica

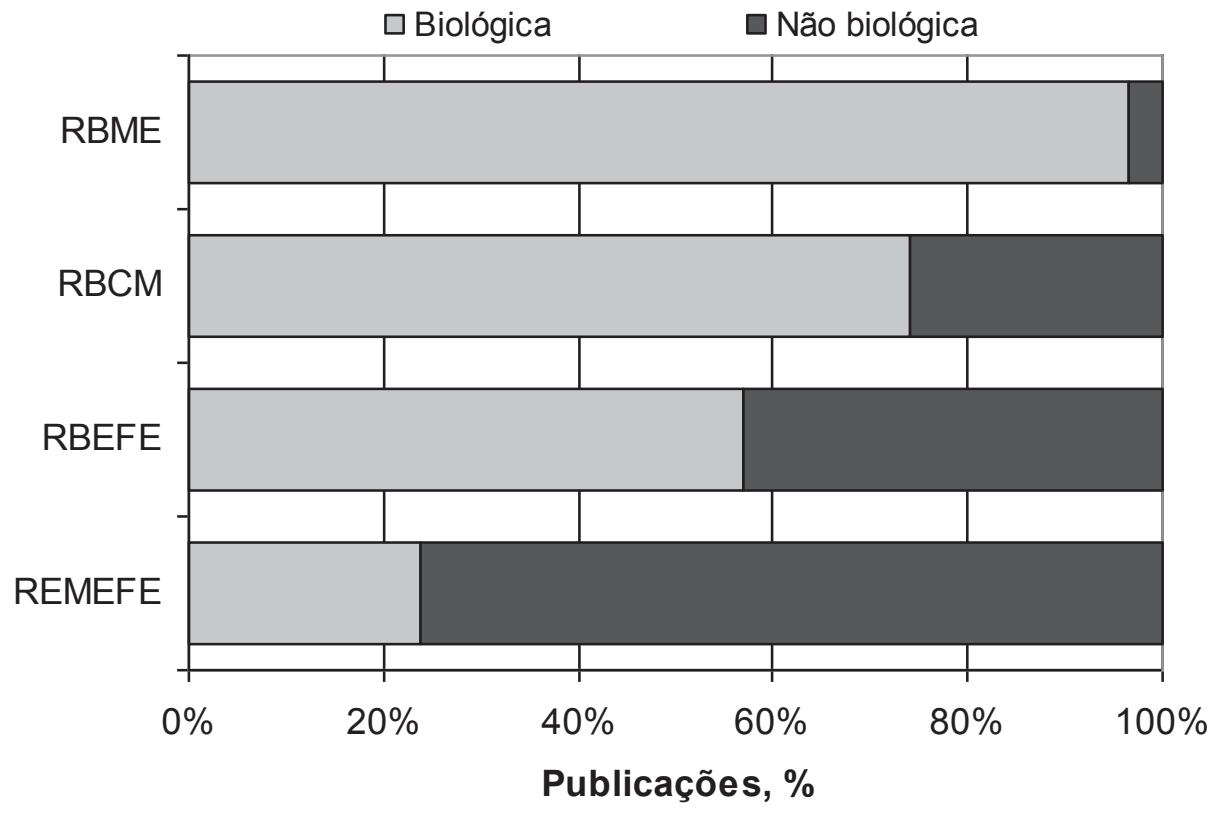

FIGURA 7 - Publicações de EF segundo a abordagem e periódico.

Cenário semelhante a este, com predominância de publicações classificadas nas áreas das ciências biológicas e reduzido número nas ciências humanas e sociais, foi também observado por FARIA JUNIOR em 1987. Neste estudo, intitulado "Pesquisa, descrição e interpretação das tendências em EF”, o pesquisador verificou que apenas $6,47 \%$ dos trabalhos em EF, publicados no período de 1975 a 1984, apresentavam preocupação de ordem filosófica/sócio-antropológicas enquanto a maioria absoluta, 64,54\%, apresentava preocupaçôes de ordem biológicas / técnicas (citado por OliveIRa, 1994).

Segundo Oliveira (1994), é a partir da reforma curricular de 1987 que os aspectos sócio-filosóficos da formação geral do novo currículo passam a ser consubstanciados em três áreas do conhecimento: conhecimentos filosóficos, conhecimentos do ser humano e conhecimentos da sociedade. No entanto, tal mudança parece ainda não se refletir na pesquisa brasileira em EF, através dos periódicos analisados.

\section{Discussão}

Os dados apresentados neste trabalho referem-se exclusivamente às informaçôes extraídas de um conjunto limitado de periódicos nacionais, credenciados por uma das principais agências de fomento à pesquisa do país, a CAPES. Esse credenciamento thes garante credibilidade e também visibilidade, uma vez que os quatro periódicos analisados neste estudo são integralmente acessíveis na Internet para qualquer cidadão da área de EF ou não. No entanto, vale mencionar que este conjunto de dados espelha uma parte do conhecimento gerado nesta área e que, 
portanto, o entendimento completo da questão central deste trabalho - e de outras que aparecem - necessitará de análises complementares, com outros enfoques e olhares, iniciativas que já estão sendo tomadas pelos autores.

Apesar destas limitações, as informações geradas neste trabalho levantam evidências acerca das tendências e das características atuais de uma parte importante da pesquisa brasileira em EF com visibilidade nacional: ela vem sendo conduzida por grupos pequenos, com maior participação de homens como primeiro autor, em formato de trabalhos originais, com grande concentração institucional, mas pouca colaboração internacional.

No conjunto das publicações, é possível observar uma maior valorização dos saberes advindos das ciências biológicas e, em especial, da fisiologia (são 376 publicaçōes). Por outro lado, saberes procedentes de outras grandes áreas ou disciplinas mais humanísticas e/ou sociais, como a filosofia, a história, a sociologia, a psicologia, a educação, também são encontradas, porém, são ainda minoria.

A comparação de nossos achados com aqueles de FARIA JUNIOR sugere que os estudos com temáticas nas ciências humanas (psicologia, sociologia, educação) e sociais estão ganhando espaço na pesquisa em EF no Brasil. Esta parece ser uma tendência natural na área que, muito embora tenha a base de sua construção histórica nas áreas médica e biológica, é sobre as áreas humanísticas, sociais e/ou culturais que tem buscado cada vez mais respaldo para melhor entender como se dão as relaçóes entre a prática de atividade física e questôes acerca do bem-estar, lazer, envelhecimento, de comportamentos sociais, etc.

Discussões acerca de como o movimento humano deve ser tratado, sob a perspectiva de fenômeno cultural ou biológico, são frequentes na EF (BRACHT, 1999; Oliveira, 1994; Satin citado por Moreira, 2005). Entretanto, os resultados do nosso estudo confirmam a forte presença de questões relacionadas à preocupação com a atividade física numa perspectiva biológica. Fatores como o poder da história da construção da área, os currículos da graduação e pós-graduação e a crença no status proporcionado pelas pesquisas (básicas) nas ciências naturais podem ser as razões para a continuidade dessa tendência. Além disso, não devem ser desprezados fatores relativos ao perfil dos periódicos analisados. Dos quatro periódicos analisados neste estudo, dois deles, RBCM e RBME, apresentam um direcionamento temático da pesquisa em EF mais voltado para a área médica e biológica. No entanto, há de se destacar o papel destes dois periódicos na difusão dos conhecimentos produzidos pelos programas de pós-graduação em EF. Tal como será apresentado na parte 2 deste trabalho, de um total de 1.377 publicações em periódicos com filiação nas 11 pós-graduações analisadas, 167 (12,1\%) e 102 (7,4\%) foram publicadas na RBCM e RBME, respectivamente. Assim, se por um lado parte dos periódicos examinados neste estudo apresenta um viés biológico, por outro eles representam parte importante da pesquisa em EF, vinculada aos programas de pós-graduação.

Logo, considerando a ênfase na disciplina da fisiologia do exercício apontada neste estudo, cabe lembrar o dualismo grego ${ }^{4}$ no que se refere à forma dicotômica de ver o homem, divido em corpo e mente. O pesquisador ou o profissional em EF, ao considerar o indivíduo de forma dicotômica, irá, sem dúvida, adotar uma posição filosófica diferente daquele que assumir uma visão de homem enquanto uma unidade. Atualmente, muito se discute sobre o que é EF e se este seria o nome mais apropriado para designar este campo de conhecimento. SOARES et al. (2005) observam que há necessidade de uma teorização mais ampla sobre o que é EF. Apesar das limitações, o presente estudo aponta características que podem contribuir para esta discussão. Além disso, suscita algumas questôes: será que o prestígio que advém da medicina, área fundadora da EF, seria a motivação que está por trás da maior tendência de pesquisa na área das ciências biológicas? Será que esta escolha garante ao pesquisador da EF maior "status"? Por outro lado, o que explicaria uma pesquisa em EF ainda pouco interessada nos aspectos humanísticos e sociais? Escolher este caminho significaria optar por temáticas de menor prestígio e status?

A situação atual pela qual passa a EF pode ser entendida e refletida a partir da Teoria de Campo, pensada e elaborada por Pierre Bourdieu (2003). Para este sociólogo, campo é um espaço social de dominação e conflitos, que segue regras próprias de organização e de hierarquia. Um ponto importante desta teoria é o conceito de autonomia, definido como "a capacidade de refratar, retraduzindo sob uma forma específica as pressōes e ou as demandas externas" (Bourdieu, 2003, p.22). Segundo ele, quanto maior a autonomia do campo menor os efeitos de pressóes externas. Desta forma, ao analisar a Educação Física como campo, seria possível sugerir que a dualidade de concepções tem causado desequilíbrios em sua estrutura? Será que ocorrem conflitos internos por poder e legitimação?

A literatura sugere que as disputas por paradigma no campo da EF e por sua identidade são recorrentes (BETTI et al., 2004; CUNHA citado por MOREIRA, 2005; GUEDES \& Rubio, 2004; KokUbun, 2003; Massa 2002; NaHAS \& BEM, 1997; ROCHA JúNIOR, 2005; VERENGUER, 1997). Enquanto isso, nosso trabalho aponta para o predomínio da visão mecanicista de homem no cenário da pesquisa atual nacional em EF, visão que se contrasta com a demanda atual pelo entendimento do homem como um ser uno. 
ROSA, S. \& LETA, J.

\section{Abstract \\ Trends on the Brazilian research in physical education. Part 1: a view through national journals}

After few centuries of its foundation, the discipline of Physical Education (PE) resides with a dichotomic approach: on the one hand, the tradition of its medical and biological aspects and on the other hand, socio-cultural, political and philosophical issues are highlighted. This seems to disrupt the historical concept of "the biologized body". Within this context, we have started an investigation of trends in Brazilian research on PE. Using a bibliometric approach, in the present paper we analyze scientific publications from four Portuguese-language journals, in the 2001-2005 period. Our aim is identify with of the two concepts prevail in Brazilian current research on EP. The following steps were taken: a) data-gathering and categorization; and b) quantitative and qualitative analyses. We found that $431(72.43 \%)$ out of 595 of the publications analyzed were from the biological sciences. More specifically, 376 (63.19\%) were from physiology. These results point to the prevalence of a broad biological approach to $P E$, in which anatomical, biochemical, biophysical, and medical aspects at large are prevalent. Although our data does not allow us to give a complete picture of research trends in PE in Brazil, they suggest that PE's current research in the country is still biologically-oriented, revealing its strong historical concept.

Uniterms: Physical education; Scientific communication; National journals; Bibliometrics.

\section{Notas}

1. Resumidamente tais propósitos podem ser definidos como: 1) o militar, no qual a atividade física aparece associada à construção de corpos fortes para o combate nas guerras; 2) o higiênico, onde a formação de um corpo disciplinado, forte e saudável do trabalhador, a partir da atividade física, é requisito indispensável para atender às demandas das classes dominantes; 3) o eugênico, no qual a atividade física relaciona-se diretamente ao projeto de melhoria da raça; 4) o terapêutico, onde a prática da atividade física está associada ao tratamento de doenças; 5) o pedagógico, no qual a atividade física é entendida como uma prática eminentemente educativa; 6) o rendimento esportivo que usa o treinamento físico para alcançar a eficiência na performance e melhorar os resultados dos atletas; 7) o "fitness" que busca na prática da atividade física a melhoria da aptidão física e da saúde; e a 8) estética corporal modelo no qual a prática de atividade física é usada para se alcançar um corpo que atenda aos padrões estéticos da atualidade.

2. De acordo com Martins (2006), desde 2001, o Portal Periódicos CAPES tem se constituído como a principal ferramenta de acesso para pesquisadores, estudantes e docentes de instituiçóes públicas e privadas de ensino superior e de pesquisa, com uma coleção de 125.722 periódicos nacionais e internacionais nas mais diferentes áreas do conhecimento. Apesar do grande volume de periódicos, disponibilizados pela CAPES, o Portal não cobre, por diversas razões, inclusive econômicas, $100 \%$ dos periódicos das áreas; portanto, o Portal não cobre todo o conhecimento gerado.

3. Detalhes sobre o "modus operantis" das ciências sociais e humanas e das ciências biológicas e exatas, inclusive a questão de autoria, são apresentadas e discutidas em diversas obras, tal com "As duas culturas e uma segunda leitura", de SNOw C.P. (1995).

4. Um exemplo é o de Platão que considerava que "a alma (mente) estava no corpo como num cárcere" (PADOVANI \& Castagnola, 1978 p.118).

\section{Referências}

BETTI, M. Corpo, cultura, mídias e educação física: novas relaçōes no mundo contemporâneo. Lecturas, Educación Fisica y Deportes: Revista Digital, Buenos Aires, v.10, n.79, 2004. Disponível em: http://www.efdeportes.com/efd79/corpo.htm>. BETTI, M.; CARVALHO, Y.M.; DAOLIO, J.; PIRES, G.L. A avaliação da educação física em debate: implicações para a subárea pedagógica e sociocultural. Revista Brasileira de Pós-Graduação, Brasília, v.1, n.2, p.183-94, 2004.

BOURDIEU, P. Os usos sociais da ciência: por uma sociologia clínica do campo científico. São Paulo: Editora UNESP, 2003. (Tradução brasileira de conferência e debate organizados pelo grupo Sciences en Question, no Institut National de la Recherche Agronomique (INRA), em Paris, aos 11 dias de março de 1997). 
BRACHT, V. A constituição das teorias pedagógicas da educação física. Cadernos Cedes, Campinas, v.19, n.48, p.69-88, 1999.

Educação física e ciência: cenas de um casamento (in)feliz. 3. ed. Ijuí: Editora Unijuí, 2007.

CAMBI, F. História da pedagogia. São Paulo: Editora UNESP, 1999.

CONSELHO NACIONAL DE DESENVOLVIMENTO CIENTÍFICO E TECNOLÓGICO (CNPq). Diretório de

Grupos de Pesquisa: 2004. Disponível em: <http://dgp.cnpq.br/censos/>. Acesso em: jan. 2008.

COORDENAÇÃO DE APERFEIÇOAMENTO DE PESSOAL DE NÍVEL SUPERIOR (CAPES). Portal periódicos

CAPES. Disponível em: <http://www.periodicos.capes.gov.br/>. Acesso em: maio 2006.

DACOSTA, L. Significados históricos de “Arquivos da ENEFD” no contexto da educação física brasileira. Arquivos em

Movimento, Rio de Janeiro, v.1, n.1, p.95-8, 2005.

FERREIRA NETO, A. Publicações periódicas de ensino, de técnicas e de magazines em educação física e esporte. In: DACOSTA, L. Atlas do esporte no Brasil. Rio de Janeiro: Shape, 2005.

FERREIRA NETO, A.; NASCIMENTO, A.C.S. Periódicos científicos da educação física: proposta de avaliação. Movimento, Porto Alegre, v.8, n.2, p.35-49, 2002.

GHIRALDELLI JÚNIOR, P. Educação física progressista: a pedagogia crítico-social dos conteúdos e a educação física brasileira. São Paulo: Loyola, 1991.

GLÄNZEL, W.; LETA, J.; THIJS, B. Science in Brazil. Part 1: a macro-level comparative study. Scientometrics, Amsterdam, v.6, n.1, p.67-86, 2006.

GUEDES, C.M.; RUBIO, K. Estudos socioculturais da educação física na Escola de Educação Física e Esporte: o que foi, o que tem sido e o que deverá ser. Revista Paulista de Educação Física, São Paulo, v.18, p.83-8, 2004. Número especial. INSTITUTE FOR SCIENTIFIC INFORMATION (ISI). Web of knowledge: 2008. Disponível em: <http://www. isiwebofknowledge.com/>.

INSTITUTO NACIONAL DE ESTUDOS PEDAGÓGICOS (INEP). Sinopses estatísticas da educação superior: graduação: 2006. Disponível em: <http://www.inep.gov.br/superior/censosuperior/sinopse/default.asp>.

KATZ, S.; MARTIN, B.R. What is research collaboration? Research Policy, Amsterdam, v.26, p.1-18, 1997.

KOKUBUN, E. Pós-graduação em educação física no Brasil: indicadores objetivos dos desafios e das perspectivas. Revista Brasileira de Ciências do Esporte, Campinas, v.24, n.2, p.9-26, 2003.

LETA, J.; GLÄNZEL, W; THIJS, B. Science in Brazil. Part 2: Sectoral and institutional research profiles. Scientometrics, Amsterdam, v.67, n.1, p.87-105, 2006.

LETA, J.; MENEGHINI, R. A produção científica no Estado de São Paulo. In: INDICADORES de ciência, tecnologia e inovação em São Paulo: 2001, 2002. São Paulo: FAPERJ, 2002.

LOTKA, A.J. The frequency distribution of scientific productivity. Journal of the Washington Academy of Science, Washington, v.16, n.12, p.317-23, 1926.

MARINHO, I.P. História geral da educação física. São Paulo: Cia. Brasil, 1980.

MARTINS, M.F.M. Estudo do uso do Portal da Capes no processo de geração de conhecimento por pesquisadores da área biomédica: aplicando a técnica do incidente crítico. 2006. Dissertação (Mestrado em Ciência da Informação) - Universidade Federal Fluminense, Rio de Janeiro, 2006.

MASSA, M. Caracterização acadêmica e profissional da educação física. Revista Mackenzie de Educação Física e Esporte, São Paulo, v.1, n.1, p.29-38, 2002.

MELO, V.A. Os arquivos da Escola Nacional de Educação Física e Desportos (1945-1966): a importância de uma revista e iniciativas de preservação. Arquivos em Movimento, Rio de Janeiro, v.1, n.1, p.33-43, 2005.

MOREIRA,W.W. (Org.). Educação física e esportes: perspectivas para o século XXI. São Paulo: Papirus, 2005.

NAHAS, M.V.; BEM, M.F.L. Perspectivas e tendências da relação teoria e prática na educação física. Motriz, Rio Claro, v.3, n.2, p.73-9, 1997.

OLIVEIRA, V.M. Consenso e conflito da educação física brasileira. São Paulo: Papirus, 1994.

PADOVANI, U.; CASTAGNOLA, L. História da filosofia. São Paulo: Melhoramentos, 1978.

ROCHA JUNIOR, C.P. A organização do campo da educação física: considerações sobre o debate. Arquivos em Movimento, Rio de Janeiro, v.1, n.2, p.69-78, 2005.

SNOW C.P. As duas culturas e uma segunda leitura. São Paulo: EDUSP, 1995.

SOARES, C.L.; TAFFAREL, C.N.Z.; VARJAL, E.; CASTELLANI FILHO, L.; ESCOBAR, M.O.; BRACHT, V. Metodologia do ensino da educação física. São Paulo: Cortez, 1992.

VERENGUER, R.C.G. Dimensões profissionais e acadêmicas da educação física no Brasil: uma síntese das discussões. Revista Paulista de Educação Física, São Paulo, v.11, n.2, p.164-75, 1997. 
ROSA, S. \& LETA, J.

\section{Agradecimentos}

As autoras agradecem à Dra Verônica Salerno Pinto pela valiosa contribuição nos critérios de classificação, ao doutorando Carlos Henrique Lobo e aos doutores Sonia M. R. Vasconcelos, Martha M. Sorenson e Victor Andrade de Melo pela revisão e análise crítica do manuscrito.

\begin{tabular}{|c|c|}
\hline $\begin{array}{r}\text { ENDEREÇO } \\
\text { Jacqueline Leta } \\
\text { Av. Brigadeiro Trompowisky, s/n. } \\
\text { Prédio do CCS - Bloco B - sala } 39 \\
\text { Cidade Universitária - Ilha do Fundão } \\
\text { 21941-590 - Rio de Janeiro - RJ - BRASIL } \\
\text { e-mail: jleta@bioqmed.ufrj.br }\end{array}$ & $\begin{array}{l}\text { Recebido para publicação: 18/05/2009 } \\
\text { Aceito: 28/10/2009 }\end{array}$ \\
\hline
\end{tabular}

134 • Rev. bras. Educ. Fís. Esporte, São Paulo, v.24, n.1, p.121-34, jan./mar. 2010 